\title{
Economic governance: the organization of cooperation
}

Traditionally, economic theory has by and large been a theory of markets or, more precisely, about market prices. However, there are at least two reasons why economic science should extend beyond price theory. First, markets do not function properly unless suitable contracts can be formulated and enforced. Hence, we need to understand the institutions that support markets. Second, considerable economic activity takes place outside of markets - within households, firms, associations, agencies, and other organizations. Hence, we need theories to explain why these entities exist and how they work.

This year's Laureates have been instrumental in establishing economic governance as a field of research. Elinor Ostrom has provided evidence on the rules and enforcement mechanisms that govern the exploitation of common pools by associations of users. Oliver Williamson has proposed a theory to clarify why some transactions take place inside firms and not in markets. Both scholars have greatly enhanced our understanding of non-market institutions.

\section{Governing the commons}

Many natural resources, such as fish stocks, pastures, woods, lakes, and groundwater basins are managed as common property. That is, many users have access to the resource in question. If we want to halt the degradation of our natural environment and prevent a repetition of the many collapses of natural-resource stocks experienced in the past, we should learn from the successes and failures of common-property regimes. Ostrom's work teaches us novel lessons about the deep mechanisms that sustain cooperation in human societies.

It has frequently been suggested that common ownership entails excessive resource utilization, and that it is advisable to reduce utilization either by imposing government regulations, such as taxes or quotas, or by privatizing the resource. The theoretical argument is simple: each user weighs private benefits against private costs, thereby neglecting the negative impact on others.

However, based on numerous empirical studies of natural-resource management, Elinor Ostrom has concluded that common property is often surprisingly well managed. Thus, the standard theoretical argument against common property is overly simplistic. It neglects the fact that users themselves can both create and enforce rules that mitigate overexploitation. The standard argument also neglects the practical difficulties associated with privatization and government regulation.

\section{Failed collectivization and privatization}

As an example of Ostrom's concerns, consider the management of grasslands in the interior of Asia. Scientists have studied satellite images of Mongolia and neighboring areas in China and Russia, where livestock has been feeding on large grassland areas for centuries. Histori- 
cally, the region was dominated by nomads, who moved their herds on a seasonal basis. In Mongolia, these traditions were largely intact in the mid-1990s, while neighboring areas in China and Russia - with closely similar initial conditions - had been exposed to radically different governance regimes. There, central government imposed state-owned agricultural collectives, where most users settled permanently. As a result, the land was heavily degraded in both China and Russia.

In the early 1980s, in an attempt to reverse the degradation, China dissolved the People's Communes and privatized much of the grassland of Inner Mongolia. Individual households gained ownership of specific plots of land. Again, as in the case of the collectives, this policy encouraged permanent settlement rather than pastoral wandering, with further land degradation as a result. As satellite images clearly reveal, both socialism and privatization are associated with worse long-term outcomes than those observed in traditional group-based governance.

\section{Failed modernization}

There are many other examples which indicate that user-management of local resources has been more successful than management by outsiders. A striking case is that of irrigation systems in Nepal, where locally managed irrigation systems have successfully allocated water between users for a long time. However, the dams - built from stone, mud and trees - have often been primitive and small.

In several places, the Nepalese government, with assistance from foreign donors, has therefore built modern dams of concrete and steel. Despite flawless engineering, many of these projects have ended in failure. The reason is that the presence of durable dams has severed the ties between head-end and tail-end users. Since the dams are durable, there is little need for cooperation among users in maintaining the dams. Therefore, head-end users can extract a disproportionate share of the water without fearing the loss of tail-end maintenance labor. Ultimately, the total crop yield is frequently higher around the primitive dams than around the modern dams.

Both of the above-mentioned failures refer to economically poor regions of the world. However, the lessons are much more far-reaching. Ostrom's first study concerned the management of groundwater in parts of California and also highlighted the role of users in creating workable institutions.

\section{Active participation is the key}

While Ostrom has carried out some field work herself, her main accomplishment has been to collect relevant information from a diverse set of sources about the governance - successful and failed - of a large number of resource pools throughout the world and to draw insightful conclusions based on systematic comparisons.

The lesson is not that user-management is always preferable to all other solutions. There are many cases in which privatization or public regulation yield better outcomes than user management. For example, in the 1930s, failure to privatize oil pools in Texas and Oklahoma caused massive waste. Rather, the main lesson is that common property is often managed on the basis of rules and procedures that have evolved over long periods of time. As a result they are more adequate and subtle than outsiders - both politicians and social scientists - have tended to realize. Beyond showing that self-governance can be feasible and successful, Ostrom also elucidates 
the key features of successful governance. One instance is that active participation of users in creating and enforcing rules appears to be essential. Rules that are imposed from the outside or unilaterally dictated by powerful insiders have less legitimacy and are more likely to be violated. Likewise, monitoring and enforcement work better when conducted by insiders than by outsiders. These principles are in stark contrast to the common view that monitoring and sanctioning are the responsibility of the state and should be conducted by public employees.

An intriguing outcome of these field studies concerns the willingness of individual users to engage in monitoring and sanctioning, despite only modest rewards for doing so. In order to ascertain more about individuals' motivations for taking part in the enforcement of rules, Ostrom has conducted innovative laboratory experiments on cooperation in groups. A major finding is that many people are willing to incur private costs in order to sanction free-riders.

\section{Markets versus hierarchies}

Nowadays, a large fraction of economic activity takes place within firms. Oliver Williamson has facilitated our understanding of why this is so. More broadly, he has taught us to regard markets, firms, associations, agencies, and even households from the perspective of their contribution to the resolution of conflict.

Why are there large firms? Couldn't we all be self-employed, trading our goods and services in the market? A general answer to this question was proposed more than seventy years ago by Ronald Coase, who received the 1991 Prize in Economic Sciences. According to Coase, firms tend to emerge whenever transaction costs, i.e., the costs of exchanging goods, services, and money, are lower inside a firm than in the corresponding market. But what exactly are those transaction costs that may tip the balance between markets and hierarchies? While Coase offered tentative suggestions, the question remained elusive.

An appropriate answer should explain why some firms grow by integrating many stages of production, whereas other firms in the same industry focus on only one or a few production stages, thereby leaving other stages to suppliers or customers. As an example, take the energy sector, where some companies operate both coal mines and coal-burning power plants, whereas other similar mines and plants are operated as separate firms.

\section{Efficient conflict resolution}

In the early 1970s, Oliver Williamson argued that hierarchical organizations sometimes dominate markets because they provide a cheaper way to resolve conflicts. If two employees quarrel about the allocation of tasks or the distribution of revenues, a chief executive is entitled to decide. In a market, on the other hand, negotiations have to continue until both parties agree. Haggling costs can be substantial, and there is no guarantee that the final agreement will be either immediate or efficient.

This argument may seem to suggest that all transactions should take place in a single giant firm. But this is clearly not an accurate description of the world as we know it. The last decade has witnessed just the opposite. Considerable outsourcing has taken place, sometimes by merely selling part of a company, while activities continue in all units much as before. That is, outsourcing creates a market transaction replacing an internal transaction. In order for 
this kind of outsourcing to make any sense, there must be drawbacks associated with hierarchical organization too.

A common view had been that hierarchical organization is costly because it entails administrative costs. Williamson realized that this view was unsatisfactory, because it is eminently possible to move the boundaries of firms without changing administrative routines. Instead, Williamson argued that the primary reason why hierarchies are problematic is that executive authority can be abused - for example by extracting surplus from subordinates in unproductive ways.

\section{Mutual dependence behind hierarchical organizations}

How can these rather broad assertions be transformed into a theory of governance that yields nontrivial and falsifiable implications? Williamson's key insight is that the value of conflict resolution depends on two main factors. First, there is no point in being able to resolve conflicts that never arise. If it is easy and cheap to regulate future transactions through a contract, there is little need for a firm. Thus, there will not arise firms unless there are limitations to contracting. Second, there is no reason to be able to resolve conflicts if disagreement is costless. If both the seller and the buyer can easily find other suitable trading partners, the firm is again superfluous.

In other words, Williamson expects hierarchical organizations to emerge when transactions are complex or non-standard, and when parties are mutually dependent. Perhaps the most typical case of mutual dependence is that parties have assets, either physical assets or knowledge, which are only valuable inside a relationship.

Let us see whether this theory can explain the boundaries of firms in the energy market described above. The value of a coal mine in case the owner cannot agree on the terms of trade with a nearby power plant depends on the distance to the second-nearest buyer of coal, which is usually another power plant. Likewise, the value of a coal-burning power plant in case it cannot trade with the nearby coal mine depends on the distance to the second nearest mine. The larger the distances, the greater is the mutual dependence, and - according to the theory - the more likely the mine and the plant are vertically integrated. This is precisely what is observed. When there are other nearby mines and power plants, firms are typically incorporated separately and trade under relatively short and simple contracts. As the distance to alternative trading partners increases, contract duration and complexity also increase. According to one of the studies, a coal-burning power plant that is located next to a coal mine is about six times more likely to be fully integrated than is any other coal-burning power plant.

\section{Policy implications}

Williamson's theory of the firm has been tested extensively in many other industries too, and the empirical support is strong. Activities are more likely to be organized inside firms when transactions are complex and assets are relationship-specific. Moreover, Williamson's general framework has proven productive in analyzing all sorts of incomplete contracts, ranging from implicit contracts between household members to financial contracts between entrepreneurs and investors.

According to Williamson's theory, large private corporations exist primarily because they are efficient. They are established because they make owners, workers, suppliers, and customers 
better off than they would be under alternative institutional arrangements. When corporations fail to deliver efficiency gains, their existence will be called in question.

Large corporations may of course abuse their power. They may for instance participate in undesirable political lobbying and exhibit anticompetitive behavior. However, according to Williamson's analysis, it is advisable to regulate such behavior directly rather than through policies that limit the size of corporations.

\section{LINKS AND FURTHER READING}

More information about this year's prizes, including a scientific background article in English, is to be found at the Royal Swedish Academy of Sciences' website, http://kva.se and at http://nobelprize.org where you can also see the press conference as web-TV. Further information about exhibitions and activities concerning the Nobel Prizes is available at www.nobelmuseum.se.

\section{Books}

Ostrom, E. (1990) Governing the Commons: The Evolution of Institutions for Collective Action, Cambridge University Press, 298 p.

Williamson, O. E. (1998) The Economic Institutions of Capitalism, Free Press, New York. 468 p.

\section{Scientific review articles}

Ostrom, E. et al. (1999) Revisiting the Commons: Local Lessons, Global Challenges, Science 284: 278-282.

Williamson, 0. E. (2005) The Economics of Governance, American Economic Review 95: 1-18.

\section{THE LAUREATES}

\section{ELINOR OSTROM}

Indiana University

Workshop in Political Theory and Policy Analysis

513 North Park Avenue

Bloomington, IN 47408-3895

USA

www.cogs.indiana.edu/people/homepages/ostrom.html

US citizen. Born in 1933 in Los Angeles, CA, USA. Ph.D. in Political Science in 1965 from the University of California, Los Angeles, USA. Arthur F. Bentley Professor of Political Science and Professor at the School of Public and Environmental Affairs, both at Indiana University, Bloomington, USA. Founding Director of the Center for the Study of Institutional Diversity, Arizona State University, Tempe, USA.

\section{OLIVER E. WILLIAMSON}

University of California Berkeley

Walter A. Haas School of Business

S545 Student Services Bldg.

Berkeley, CA 94720-1900

USA

www2.haas.berkeley.edu/Faculty/williamson_oliver.aspx

US citizen. Born in 1932 in Superior, WI, USA. Ph.D. in Economics in 1963 from Carnegie Mellon University, Pittsburgh, PA, USA. Edgar F. Kaiser Professor Emeritus of Business, Economics and Law since and Professor of the Graduate School, both at the University of California, Berkeley, USA. 